\title{
BMJ Open Preventing emergency department (ED) visits and hospitalisations of older adults with cognitive impairment compared with the general senior population: what do we know about avoidable incidents? Results from a scoping review
}

\author{
Mireille Gagnon-Roy, ${ }_{1}^{1}$ Benyahia Hami, ${ }^{2}$ Mélissa Généreux ${ }^{3}$ Nathalie Veillette, ${ }^{1}$ \\ Marie-Josée Sirois, ${ }^{4}$ Mary Egan, ${ }^{5}$ Véronique Provencher ${ }^{2}$
}

To cite: Gagnon-Roy M, Hami B, Généreux M, et al. Preventing emergency department (ED) visits and hospitalisations of older adults with cognitive impairment compared with the general senior population: what do we know about avoidable incidents? Results from a scoping review. BMJ Open 2018;8:e019908. doi:10.1136/ bmjopen-2017-019908

- Prepublication history and additional material for this paper are available online. To view these files, please visit the journal online (http://dx.doi org/10.1136/bmjopen-2017019908).

Received 4 0ctober 2017 Revised 22 January 2018 Accepted 8 February 2018

Check for updates

For numbered affiliations see end of article.

Correspondence to Professor Véronique Provencher; veronique.provencher@ usherbrooke.ca

\section{ABSTRACT}

Objectives Older cognitively impaired adults present a higher risk of hospitalisation and mortality following a visit to the emergency department (ED). Better understanding of avoidable incidents is needed to prevent them and the associated ED presentations in community-dwelling adults. This study aimed to synthetise the actual knowledge concerning these incidents leading this population to ED presentation, as well as possible preventive measures to reduce them.

Design A scoping review was performed according to the Arksey and 0'Malley framework.

Methods Scientific and grey literature published between 1996 and 2017 were examined in databases (Medline, Cumulative Index of Nursing and Allied Health, Ageline, Scopus, ProQuest Dissertations/theses, Evidence-based medecine (EBM) Reviews, Healthstar), online library catalogues, governmental websites and published statistics. Sources discussing avoidable incidents leading to ED presentations were included and then extended to those discussing hospitalisation and mortality due to a lack of sources. Data (type, frequency, severity and circumstances of incidents, preventive measures) was extracted using a thematic chart, then analysed with content analysis.

Results 67 sources were included in this scoping review. Five types of avoidable incidents (falls, burns, transport accidents, harm due to self-negligence and due to wandering) emerged, and all but transport accidents were more frequent in cognitively impaired seniors. Differences regarding circumstances were only reported for burns, as scalding was the most prevalent mechanism of injury for this population compared with flames for the general senior population. Multifactorial interventions and implications of other professionals (eg, pharmacist, firefighters) were reported as potential interventions to reduce avoidable incidents. However, few preventive measures were specifically tested in this population.
Strengths and limitations of this study

This study provides an accurate overview of the current knowledge about avoidable incidents leading older adults, with and without cognitive impairment, to an ED presentation and hospitalisation, as well as preventive measures that may be implemented to avoid these incidents.

- This study followed a rigorous method, guided by two experienced librarians, completed independently by at least two reviewers at each step and reviewed by experienced researchers and stakeholders in the field.

- Some avoidable incidents were not discussed in this scoping review, as they were not differentiable from medical conditions (eg, urinary tract infection due to dehydration).

- Considering the lack of sources focusing on ED presentation and avoidable incidents, sources discussing hospitalisations were included for some types of incidents (eg, burns) to better understand them.

Conclusions Primary research that screens for cognitive impairment and involves actors (eg, paramedics) to improve our understanding of avoidable incidents leading to ED visits is greatly needed. This knowledge is essential to develop preventive measures tailored to the needs of older cognitively impaired adults.

\section{INTRODUCTION}

As the worldwide population ages, an increasing number of older adults (65+) are consulting at emergency departments (ED). In Canada, this population is 1.5 times more likely to visit the ED than the younger population. ${ }^{1}$ Furthermore, among these 
older adults, between $21 \%$ and $42 \%$ present with cognitive impairment, which exacerbates the risk of negative outcomes following an ED visit and reduces the probability of returning home. ${ }^{2-6}$ Considering the high costs and negative consequences associated with this subpopulation's use of ED and hospital healthcare services, ${ }^{1}$ it is crucial to prevent potentially avoidable incidents leading to ED visits and hospitalisations, especially in older adults with cognitive impairment.

Avoidable incidents, which may refer to unintentional injuries due to falls, motor vehicle traffic crashes, toxic substances, fire/hot objects or other external causes, ${ }^{7}$ represent a large proportion (over 20\%) of ED visits by older adults. ${ }^{8-11}$ Those with cognitive impairment often present judgement errors and self-neglect behaviours, which may put them at a higher risk of various avoidable injuries (eg, burning themselves while cooking due to forgetting to turn off electrical appliances, poisoning after eating spoiled food in the refrigerator, falls caused by failure to use walking aids). ${ }^{1213}$ Many preventive measures (eg, fall prevention programmes and driving classes for seniors) have been developed and implemented to reduce avoidable incidents in community-dwelling adults. ${ }^{14-16}$ However, these preventive measures may not be tailored to the specific needs of older adults with cognitive impairment, as most were not developed for this vulnerable population or may exclude it altogether. ${ }^{14}{ }^{15}$ As a result, little is known about best measures to implement to reduce avoidable incidents and related $\mathrm{ED}$ visits in this subpopulation. Increased knowledge about avoidable incidents leading older adults with cognitive impairment to ED presentations and the circumstances in which they occur compared with the senior population in general will help to identify appropriate preventive measures that could be implemented upstream.

This study aims at synthesising the current knowledge related to avoidable incidents leading to ED presentations by older people with cognitive impairment living in the community, as well as potential preventive measures aiming at reducing them. More specifically, we aimed to identify (1) the type, frequency and severity of avoidable incidents associated with presentations to the ED, by older adults with cognitive impairment, compared with the general senior population, (2) the circumstances in which they occurred and (3) if they could have been avoided by safe and healthy environments or behaviours.

\section{METHODOLOGY}

As an initial step to identify priorities for the development of a comprehensive preventive approach, a scoping review was completed using the six stages refined by Levac et $a l^{17}$ according to Arksey and O'Malley methodology. ${ }^{18}$ This project's protocol was published in $2016 .{ }^{19}$

This scoping review first aimed to answer the main research question: "What is the actual knowledge on avoidable incidents leading to ED presentation by older adults living in the community, particularly those with cognitive impairment, to implement preventive measures that are tailored to their needs?" Four specific questions were then identified:

1. What are the main types of avoidable incidents associated with presentations to the ED by seniors with cognitive impairment compared with the general senior population (eg, fall-related injuries, food poisoning, heat stroke)?

2. Are they more or less frequent and serious compared with older adults without cognitive impairment?

3. Do they occur in specific circumstances (eg, during the day/night, in the summer/winter, indoor/outdoor, when driving/cooking)?

4. Could they have been avoided by safe and healthy environments or behaviours?

For this review, incidents were defined as physical injuries to self or others, property loss or property damage. More precisely, avoidable incidents referred to traumatic injuries (eg, hip, wrist), poisoning (eg, inadvertent medication overdose, biological substances) and some other consequences of external causes (eg, frostbite, burn, heat stroke) ${ }^{20}$

Using a research strategy validated by two librarians (FL and KR), scientific and grey literature published in English and in French between 1996 and 2016 was explored through a variety of databases. ${ }^{19}$ A total of 654 sources were found and exported to reference manager software (Zotero). Following the elimination of duplicates and non-English or French sources, 633 scientific sources remained (see figure 1). An update of the literature published until April 2017 was also completed, increasing the number of sources to 656 . Screening was then completed independently by two members of the research team (MGR and $\mathrm{BH}$ ) and/or two collaborators (ACLC and SS) according to our inclusion criteria. More precisely, sources were included if the participants were: (1) 65 years old and over, with or without cognitive impairment as documented by screening tests or categorised by the authors of the sources (seniors who were reported 'independent' by authors were also categorised as older adults without cognitive impairment), (2) living in the community (house, private residence, senior housing or other structured environments) and (3) presenting to the ED because of an avoidable incident. ${ }^{19}$ As incidents occurring in seniors with cognitive impairment were rarely discussed in literature, sources from other hospital settings (eg, hospitalisation) were also included when too few sources focused on ED visits. Furthermore, sources were considered if they focused on strategies and preventive measures to avoid these incidents. After screening by title and abstract, 153 sources remained. Finally, 67 sources were included for complete analysis.

Data charting was performed independently by two members of the research team (MGR and $\mathrm{BH}$ ) and/or two collaborators (SS and ACLC) using the data charting form developed according to the study's objectives. ${ }^{19}$ To insure inter-rater agreement, four articles were analysed independently by the first author and each of the reviewers. Descriptive numerical summary analysis and content 


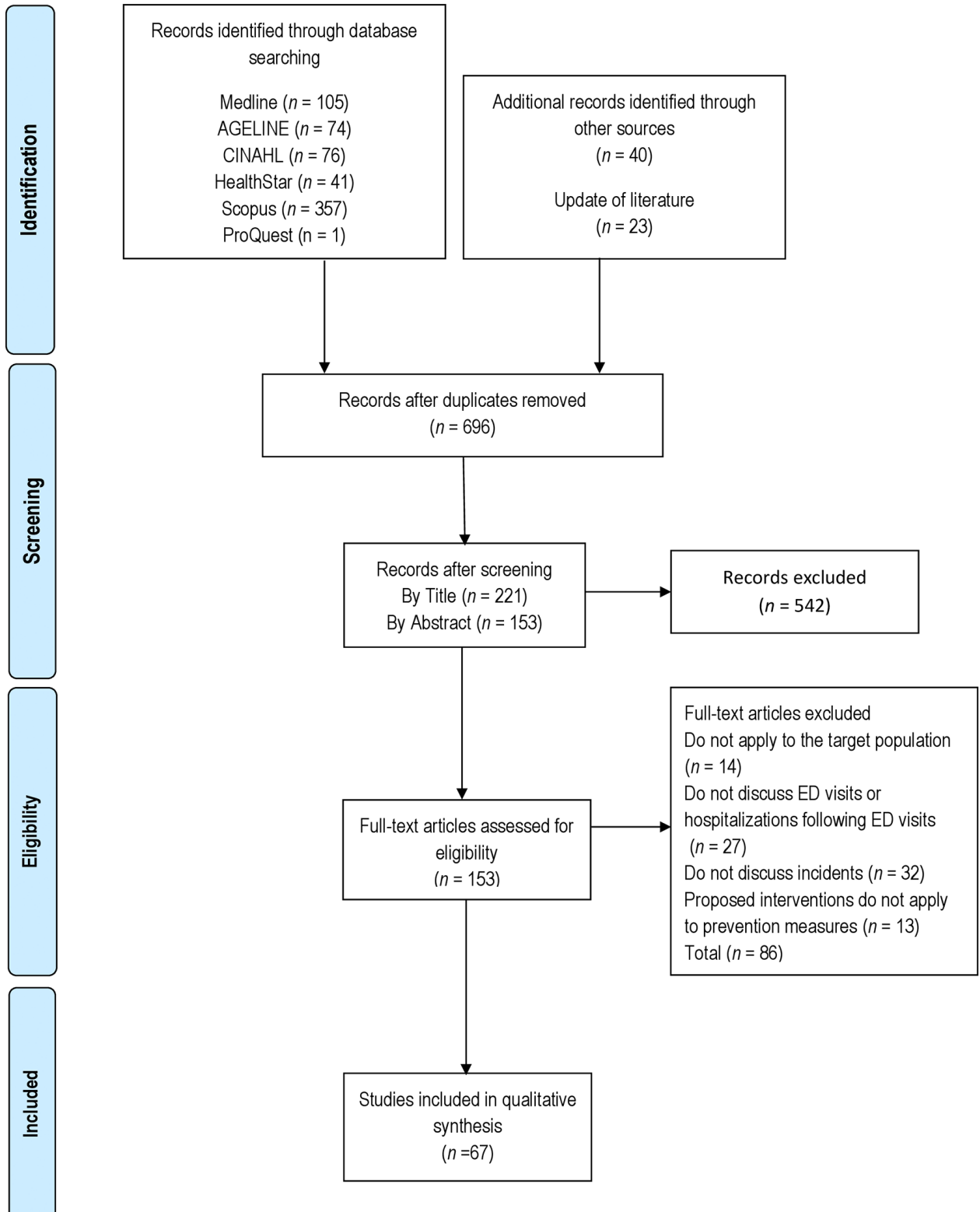

Figure 1 PRISMA flow chart of the scoping review. Summary of evidence search and selection. Selection process for studies to be included in the scoping review in compliance with PRISMA standards. CINAHL, Cumulative Index of Nursing and Allied Health; ED, emergency department; PRISMA, Preferred Reporting Items for Systematic reviews and Meta-Analyses.

analysis $^{21}$ were also independently performed by two members of the research team (MGR and $\mathrm{BH})$ as described in the protocol. ${ }^{19}$ Results were reported using descriptive statistics and narrative synthesis, according to the main type of avoidable incidents emerging from literature. Finally, results were presented to stakeholders from the Regional Public Health Department in the province of Quebec (Canada) and researchers in gerontology and ED services.

\section{RESULTS}

\section{Overview of results}

Study designs and definitions

Out of the 67 sources included in this scoping review, 29 were descriptive studies (43\%), 10 were literature reviews,
4 were empirical studies, 4 were statistical papers, 4 were expert opinions and 16 were documents from grey literature.

Population

Twenty-five sources (37\%) included participants with documented cognitive impairment, six sources included older adults without cognitive impairment as assessed by screening tests or reported as 'independent in daily living activities' by authors, while 36 documents (54\%) did not detail the cognitive status of older patients.

\section{Setting}

Twenty-four sources included data from the ED (36\%), three sources only focused on the hospital care setting 


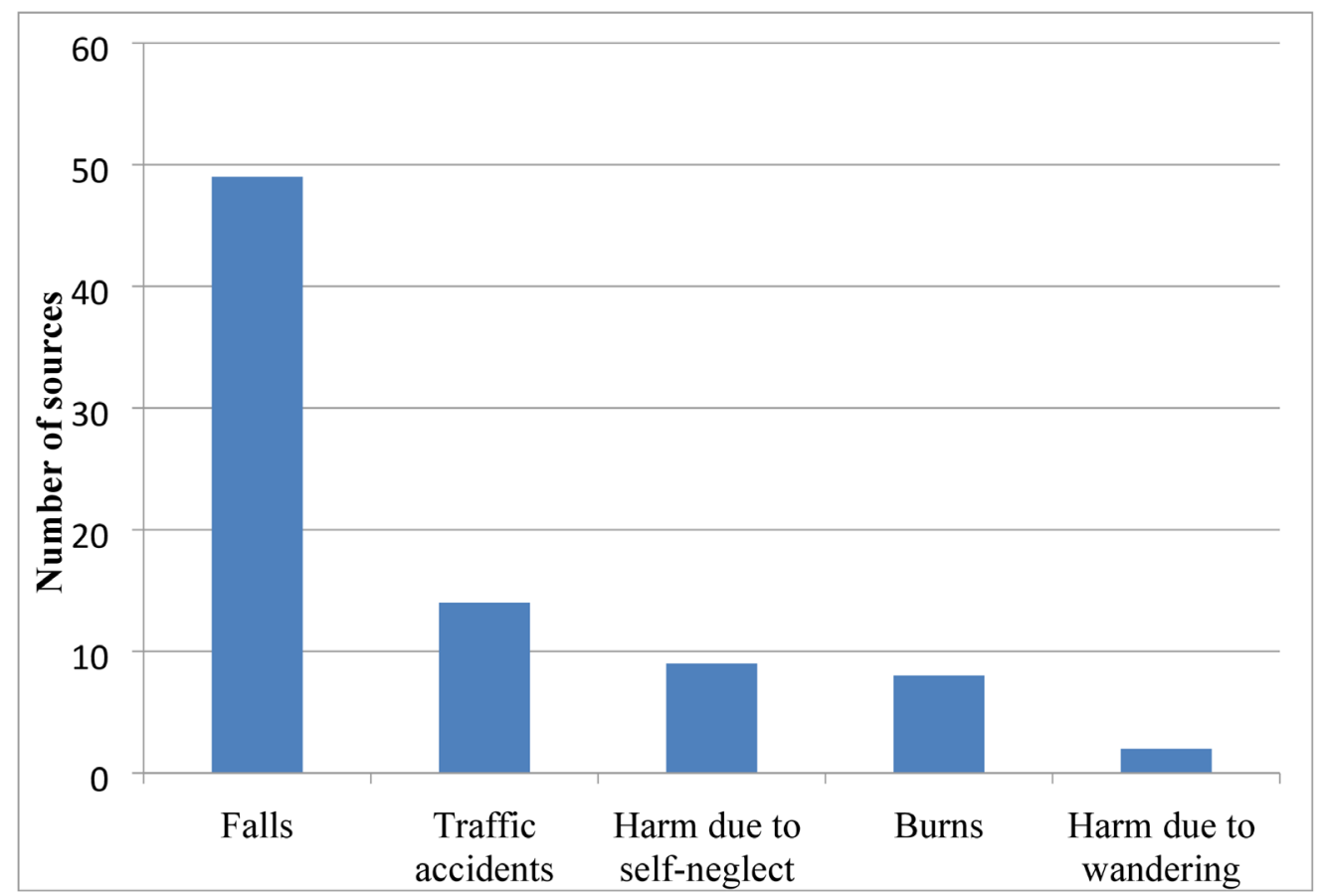

Figure 2 Number of studies mentioning avoidable incidents. Falls (the first bar at left) are the most commonly mentioned type of avoidable incidents (mentioned in 49 out of 67 total studies).

(eg, hospitalisations) (4\%), and 40 sources focused on the community $(60 \%)$.

\section{Types of incidents}

The most commonly mentioned incidents were falls, which were mentioned in 49 papers $(73 \%)$. Traffic accidents were mentioned in 14 papers $(21 \%)$, followed by harm due to self-neglect (13\%), burns (12\%) and harm due to wandering (3\%) (see figure 2). Preventive measures were discussed in 44 papers $(66 \%)$.

\section{Country of publication}

Canadian and US studies dominated the review $(\mathrm{n}=44$; $66 \%$ ), with 23 and 21 sources, respectively. Six were from the UK, three from Australia and New-Zealand, two from France and two from Sweden.

\section{Year of publication}

One-third of the sources was published in 2013-2017 $(\mathrm{n}=22 ; 33 \%)$, one quarter was published in 2008-2012 $(\mathrm{n}=18 ; 27 \%)$ and another quarter was published between 2003 and $2007(\mathrm{n}=18 ; 27 \%)$. The remaining $(\mathrm{n}=9$; $13 \%$ ) were published before 2002. Included sources are displayed in (see online supplementary files).

\section{Avoidable incidents}

Falls

Not surprisingly, falls emerged as the main type of incident among older adults, whether associated with an ED presentation and use of medical services or not $(30 \%-$ $80 \%)^{22-27}$ and as the main cause of injury (eg, fractures) ${ }^{28}$ in this population. ${ }^{27}{ }^{29-31}$ Falls were also the main cause of hospitalisations $(62 \%-80 \%)$ and ED visits $(59 \%-85 \%)$ following an incident. 811 25-27 2930 32-45 When comparing older adults, with and without cognitive impairment, the cognitively impaired were reported to fall more often $(60 \%-80 \%)$ than the non-impaired $(30 \%),{ }^{22-27}$ as well as being hospitalised more often due to falls (around 19\%) than the general senior population (14\% of total hospitalisations). ${ }^{42-44}$ Nonetheless, the difference between older adults, with and without cognitive impairment, in terms of ED visits following a fall compared with the total number of visits, is non-significant $(11.1 \%$ vs $10.4 \%$, respectively) ${ }^{39}$ Furthermore, seniors with cognitive impairment sustained more severe injuries and were three times more at risk of fractures than those without cognitive impairment. ${ }^{23}$

In terms of circumstances, no difference was documented between the two subpopulations. Falls mainly occurred at home or nearby $(47 \%-74 \%) .{ }^{25} 273234374046-49$ The toilet was the most common site $(29 \%)$, followed by the living room $(18 \%)$ and the kitchen $(14 \%) \cdot{ }^{33}$ Falls happened mostly during the day. ${ }^{30} 4550$ Ice and winter conditions were also associated with falls. ${ }^{51}$

Finally, many studies outlined the link between falls and the following factors: cognitive impairment, ${ }^{24} 323941$ 52-56 wandering, ${ }^{52}$ poor physical condition, ${ }^{24} 252932335357$ medical conditions, ${ }^{24} 252932-34464754$ polymedication and some types of medication, ${ }^{243053545859}$ living alone ${ }^{3260}$ and hazards in the environment. ${ }^{24} 3350$

\section{Transport accidents}

Traffic accidents were the second cause of ED visits $(14 \%-22.6 \%)$ and hospitalisations following an incident. ${ }^{9} 1126293035$ When comparing older adults, with 
and without cognitive impairment, those with cognitive impairment were significantly less hospitalised $(3.5 \%)$ than those without (35\% of total hospitalisations following an incident). ${ }^{41}$

In terms of circumstances, no difference pertaining to cognitive impairment was documented. Accidents mainly occurred during the day on weekends (Friday to Sunday) and between May and August. ${ }^{30}$ Meanwhile, approximately $60 \%$ of hospitalised older adults with cognitive impairment were driving at the time of the accident. ${ }^{41}$

Several factors were linked to a higher risk of traffic accidents, including cognitive impairment, ${ }^{26}{ }^{61}$ reckless behaviour ${ }^{61}$ and deteriorating physical condition. ${ }^{26}$

\section{Burns}

Burns emerged as the third cause of ED visits following an incident $(2 \%-3 \%)^{933}$ and the third cause of home injuries. ${ }^{52}$ Burns in cognitively impaired seniors were reported to cause more morbidity and mortality (25\%) than in the general senior population $(13.8 \%) .{ }^{5262}$ Differences were also noted regarding major burn mechanisms. The main major burn mechanism among cognitively impaired seniors was scalding $(44.4 \%)$, followed by flame burns $(36.1 \%)$ and contact $(18 \%),{ }^{62}$ while flames or flash were the most common in the general senior population $(51 \%-81 \%)$, followed by scalding $(11 \%-30 \%)$ and contact $(5 \%-7 \%){ }^{63}$

In both subpopulations, most burns occurred at home ${ }^{6263}$ Older adults with cognitive impairment mainly suffered burns while bathing (31\%) and cooking (16\%) ${ }^{62}$ On the other hand, $27 \%$ to $40 \%$ of major burns and $68 \%$ of minor burns in older adults without cognitive impairment occurred in the kitchen. ${ }^{63}$

Many factors were associated with burns, such as physical condition, ${ }^{63-65}$ cognitive impairment, ${ }^{52}{ }^{6465}$ polymedication, ${ }^{64}$ reckless behaviours ${ }^{6365}$ and living alone. ${ }^{6466}$

\section{Harm due to self-neglect}

In older adults with cognitive impairment, harm due to self-neglect was reported as an avoidable incident, with an incidence of $11 \%$ to $21 \%$, of which $70 \%$ needed urgent care. $^{136768}$ Major harm due to self-neglect included: failure to eat/drink, failure to follow instructions (treatment, medication or technical aids), failure to report a medical condition and failure to maintain personal hygiene. ${ }^{136768}$ Furthermore, older adults with cognitive impairment were more at risk of non-compliance to medication than those without cognitive impairment. ${ }^{52} 6970$ Finally, harm due to self-neglect can be influenced by polymedication $^{5969}$ and cognitive impairment. ${ }^{676871}$

\section{Harm due to wandering}

Older adults with cognitive impairment were more at risk to get lost and suffer from consequent harm (eg, frostbite), regardless of their living arrangements, especially when left unattended. Around 13\% were in an outing that they regularly took alone. ${ }^{72}$

\section{Preventive measures}

Preventive measures identified through this scoping review are displayed in table $1 \mathrm{~A}$ (individual interventions) and table 1B (environmental interventions). Most of

Table 1A Individual-level interventions organised by types of incidents

\begin{tabular}{|c|c|c|c|}
\hline & \multicolumn{3}{|l|}{ Individual-level interventions } \\
\hline & Physical/medical & Cognitive & Assistive devices \\
\hline Falls & 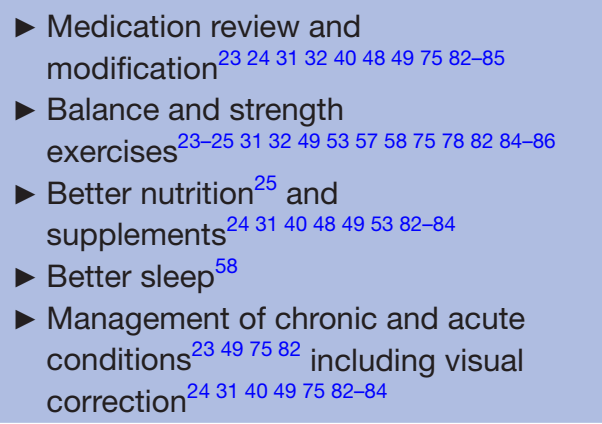 & $\begin{array}{l}\text { Education on risks } \\
\text { and prevention } \\
\text { measures }^{23} 334849758687 \\
\text { Education on dementia } \\
\text { - Fear of falling assessment }\end{array}$ & $\begin{array}{l}\text { Mobility-aid devices }{ }^{327584} \\
\text { Antislip shoes and } \\
\text { devices }^{242527505883} \\
\text { Hip protectors } \\
\text { H8-50 }\end{array}$ \\
\hline Traffic accidents & $\begin{array}{l}\text { Recommendations to restrict or to stop } \\
\text { driving }^{75} \\
\text { Regular medical examination } \\
\text { R461 }\end{array}$ & $\begin{array}{l}\text { Safety education programmes } \\
\text { for seniors }\end{array}$ & \\
\hline $\begin{array}{l}\text { Harm due to self- } \\
\text { neglect }\end{array}$ & $\begin{array}{l}\text { Medication review and } \\
\text { modification } 69717588\end{array}$ & $\begin{array}{l}\text { Education of patient on } \\
\text { treatment and non-adherence } \\
\text { prevention measures }^{69}\end{array}$ & $\begin{array}{l}\text { Compliance aids (pill } \\
\text { organisers, medication } \\
\text { schemes) }^{6971}\end{array}$ \\
\hline $\begin{array}{l}\text { Harm due to } \\
\text { wandering }\end{array}$ & & & Identification bracelet ${ }^{75}$ \\
\hline
\end{tabular}




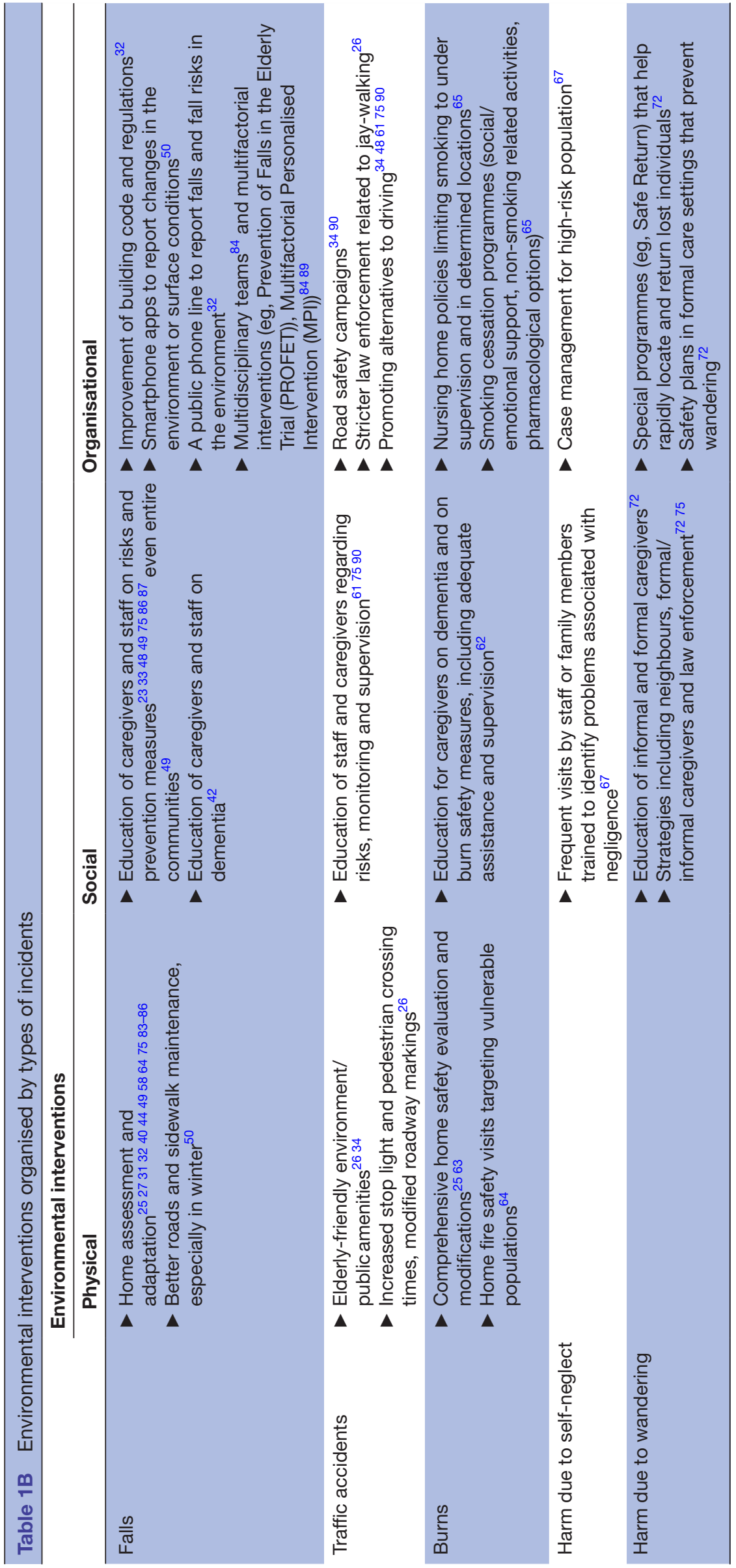

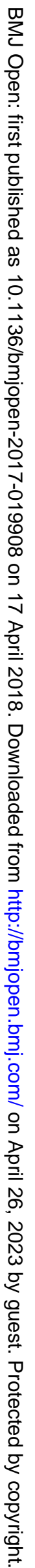


them were applied to the general senior population, and not to the older adults with cognitive impairment. Identified prevention programmes could be implemented in the person's microenvironment (at home) or macroenvironment (community).

Measures to prevent falls were the most common theme. Home assessments and adaptations $(n=16)$, as well as physical exercise, (eg, strength and balance exercises) $(\mathrm{n}=15)$ were the most frequently described interventions, followed by medication review $(n=12)$, use of assistive devices $(\mathrm{n}=11)$ and improved nutrition (eg, food supplements) $(\mathrm{n}=10)$. The second major theme pertained to preventive measures for traffic accidents $(n=6)$. Interventions included cognitive and physical screening in older adults by the physician, as well as environmental interventions, including government measures (eg, regulations and preventive campaigns). Interventions to prevent burns were also environmental, such as home assessment and modifications targeting high-risk populations (eg, using temperature controls to reduce risks of scalding). In terms of self-neglect, interventions focused on non-compliance (eg, walking aid, medication) and environmental interventions (surveillance and home visits targeting high-risk populations). Finally, preventive measures to reduce wandering mainly encompassed community involvement, (eg, neighbourhood and family) and special programmes and plans to prevent or rapidly intervene after the incident.

\section{DISCUSSION}

In this scoping review, we aimed to examine literature about avoidable incidents leading older adults with cognitive impairment to ED presentations to identify preventive measures that could be implemented to reduce such incidents. Furthermore, as incidents occurring in seniors with cognitive impairment were rarely discussed in literature, the search was extended to other hospital settings (eg, hospitalisation) when too few sources focused on ED visits. Five main types of incidents emerged from literature: falls, traffic accidents, burns, harm due to self-neglect and harm due to wandering. Of those, most were more frequent in cognitively impaired seniors, as they may present judgement errors and unsafe behaviours. ${ }^{12} 13$ The only exceptions were hospitalisations related to traffic accidents and ED presentations related to falls, for which the difference of prevalence between the two subpopulations was not significant. Differences regarding hospitalisations following traffic accidents could be explained by a significantly lower number of cognitively impaired drivers compared with older drivers without such impairment, as the dementia diagnosis was strongly associated with driving cessation. ${ }^{73}{ }^{74}$ Nonetheless, when driving, cognitively impaired adults were at increased risk of experiencing an incident (whether or not associated with an ED presentation or hospitalisation) than those without such impairment $\mathrm{t}^{41} 6175$ and may be less fit for driving. ${ }^{7677}$ On the other hand, the difference of ED presentations related to falls between both subpopulations was not significant. This could be explained by the fact that most studies in the ED were based on medical files analysis, which lacked a systematic review of cognitive status. As a result, the number of older adults with cognitive impairment or dementia may have been underestimated, therefore reducing the difference between both subpopulations in terms of ED presentations following a fall. Nevertheless, falls emerged as the main type of incident for both subpopulations. This result is congruent with its actual importance in the scientific literature $(73 \%$ of the sources reported in this scoping review), as well as its predominance in deployed preventive measures. In fact, in Canada, more than 50 community-based programmes were developed and deployed with older adults in 2001 to prevent falls, ${ }^{16}$ which seem far more numerous than programmes for other types of incidents.

One of the main objectives of this scoping review was to document the circumstances under which the incidents occurred. Unfortunately, this description remains limited and focused only on the three main types of incident (falls, traffic accidents and burns). Consequently, little is known about the activities carried out at the time of the incident. As this information could facilitate the development of preventive measures according to risk factors (eg, adapt preventive measures according to the circumstances of traffic accidents), future studies in the ED should further detail the circumstances of incidents in seniors. Moreover, one of the main limitations of our study was the difficulty to differentiate harm due to incidents from other medical causes (eg, infections, side effects to medication), as some medical conditions may be caused by avoidable incidents (eg, bad hygiene caused by self-neglect can lead to infections; non-compliance to medication can lead to a variety of sides effects).${ }^{131}$ For this scoping review, we decided to exclude all medical conditions with unknown or unclear causes. Consequently, the prevalence of avoidable incidents, such as harm due to self-neglect and wandering, may be underestimated in the cognitively impaired population. In conclusion, better identification of these incidents among cognitively impaired seniors in the ED and hospital setting, as well as the circumstances under which they occurred, may help understand the cause of injuries and reduce the risk of further ones, as preventive measures may be put in place accordingly.

In total, 43 preventive measures were identified through this scoping review. Preventive measures mainly focused on environmental modifications (eg, home and community physical environments, education to caregivers), modification of the person's habits (eg, nutrition, medication, use of technical aids), government measures (eg, safety programmes with firefighters and the authorities, building regulations) and the involvement of a multidisciplinary team at the ED (eg, pharmacist, occupational therapist, doctor). These interventions may represent a good starting point for Public Health Authorities around the world to implement safe and healthy environments. Not surprisingly, most interventions aimed 
to reduce falls among older adults $(n=19)$, regardless of their cognitive level. Furthermore, only few preventive measures were tested and evaluated among the cognitively impaired population, and results were often poorer than those obtained with older adults without cognitive impairment. ${ }^{22} 2378$ In fact, no significant reduction was observed between the intervention group and the control group in terms of fall rates, ED presentations and hospitalisations ${ }^{22}{ }^{60}$ Potential preventive measures to reduce other types of incidents were also identified (eg, home environment evaluation and modifications such as using current technologies like temperature controls to reduce the risk of burns in the bath, the recommendation to cease driving, education and supervision by caregivers to reduce self-negligence ${ }^{25636775}$ in older adults with cognitive impairment, but few were specifically tested in this subpopulation. For most of the preventive measures, outcomes were also not described, which reduce their applicability in the clinical setting. As these incidents represented the first, second and third causes of ED presentation for this population, further studies should focus on the development and implementation of new preventive measures to reduce these incidents. This knowledge could then be used by stakeholders to make an informed decision to promote public health policies (eg, home and road safety programmes), healthcare services (eg, workshops focusing on the prevention of avoidable incidents) and future research (orienting primary research and systematic review) to improve the well-being of this population and reduce avoidable costs associated with ED presentations and hospitalisations.

This study highlighted the need for primary studies, in the specific context of ED and for subgroups of older adults with cognitive impairment. A systematic screening of the cognitive abilities and the circumstances around ED presentation through the use of a short screening tool, such as the Six-Item Screener, ${ }^{79} 80$ or medical chart review, could help identify older adults with cognitive impairment. Implication of different actors in the screening process may also improve our understanding of avoidable incidents, circumstances of such incidents and case management. In Ontario (Canada), a pilot study was performed with paramedics to develop a screening tool to help identify the circumstances surrounding the incident leading to ED presentation, as well as associated risk factors in the person's environment. ${ }^{81}$ Results were positive, and further studies are ongoing. Finally, coroner's files could be used to better understand the circumstances surrounding avoidable incidents leading to death, which are the more severe cases. In summary, further primary studies are required and should involve many actors (eg, occupational therapists, pharmacists) in the $\mathrm{ED}$, considering the complexity and multifactorial nature of avoidable incidents.

Using a rigorous method, this scoping review provided the advantage of exploring a variety of sources from a multitude of databases (eg, statistics, national and provincial health organisations, scientific databases).
Covalidation of sources inclusion, data charting and analyses were also completed to ensure valid interpretation of results. The study has, however, some limitations. As previously mentioned, sources and causes of ED presentation and hospitalisations that may be associated with avoidable incidents (eg, infections, medication side effects) were excluded from this scoping review. Prevalence of incidents for older adults, with and without cognitive impairment, may have been consequently underestimated. Considering the lack of knowledge concerning ED presentation and avoidable incidents, data and sources focusing on hospital medical services and mortality were included in this scoping review and may affect our conclusions. Inclusion of these sources allowed us to explore the severity of incidents, as well as more severe cases, an aspect that is rarely discussed in literature. Furthermore, distinction between older adults, with and without cognitive impairment, may vary between included sources, as cognitive abilities were not always assessed. Therefore, some sources may have categorised older adults with mild cognitive impairment or who are undiagnosed as older adults without cognitive impairment. In accordance with the selected design, the quality of the studies was also not assessed, ${ }^{19}$ and some pertinent studies may not have been included in this scoping review. Consequently, our conclusion may have been affected by the biases of the included studies. Finally, the definition of ED presentation and the applicability of the study results may vary in different countries. This should be considered before using this knowledge in an identified healthcare system. Nonetheless, this study provides a better understanding of avoidable incidents leading older adults with cognitive impairment to ED presentation, demonstrates the need for primary research and is a good starting point to identify preventive measures to implement with this population.

\section{CONCLUSION}

This scoping review provided a detailed and comprehensive perspective of current knowledge regarding five types of avoidable incidents (falls, traffic accidents, burns, harm due to self-neglect, harm due to wandering) leading older adults, with and without cognitive impairment, to ED presentation and related hospitalisations and the preventive measures that may be implemented to reduce these incidents. According to this review, falls, traffic accidents and burns emerged as the three main types of avoidable incidents for both subpopulations. However, little is known about the circumstances in which the incidents occurred, and some (eg, frostbite, dehydration) were not specifically discussed in the literature. Considering the lack of knowledge, future primary research should focus on the screening and documentation of the circumstances and cognitive abilities of older adults presenting to the ED by involving many actors. Furthermore, although many potential preventive measures were identified, only few were tested with older cognitively impaired adults. 
Consequently, thought this scoping review aimed to reduce the rate of avoidable incidents leading to an ED presentation, too little information was available to identify the best measures to attain this objective. As a result, further studies are needed to test and implement preventive measures with this population and consequently to reduce further negative outcomes (ie, prevalence of ED presentations and hospitalisations related to avoidable incidents in cognitively impaired seniors, as well as their severity).

\section{Author affiliations}

1École de réadaptation, Faculté de médecine, Université de Montréal, Montréal, Quebec, Canada

${ }^{2}$ Faculty of Medicine and Health Sciences, University of Sherbrooke, Research Centre on Aging, Sherbrooke, Quebec, Canada

${ }^{3}$ Faculty of Medicine and Health Sciences, University of Sherbrooke, Direction de la Santé Publique de l'Estrie-CIUSS de l'Estrie-CHUS, Sherbrooke, Quebec, Canada

${ }^{4}$ Département de réadaptation, Faculté de médecine, Université Laval, CHU de Québec, Québec, Canada

${ }^{5}$ Rehabilitation Sciences, Faculty of Health Sciences, University of Ottawa, Bruyere Institute, Ottawa, Ontario, Canada

Collaborators Kathy Rose; Francis Lacasse; Stéphanie Stocco; Annie-Claude Lemieux-Courchesne.

Contributors MGR and BH completed the literature review and the data extraction, assisted by two collaborators (Stéphanie Stocco and Annie-Claude Lemieux-Courchesne) and participated in the study design. They also analysed and interpreted the results. MGR wrote the first draft of the manuscript with the help of BH. VP, NV, ME, M-JS and MG contributed to the study concept and design. Two collaborators (Kathy Rose and Francis Lacasse) were involved in the selection of relevant keywords and databases. The article was critically reviewed by NV, ME, MG, M-JS and VP.

Funding This work was supported by the Fonds de recherche du Québec (FRQ-S, no. 34546) and the Faculty of Medicine and Health Sciences of the University of Sherbrooke (UBR-706230).

Competing interests None declared.

Patient consent Not required.

Provenance and peer review Not commissioned; externally peer reviewed.

Data sharing statement № additional data available.

Open Access This is an Open Access article distributed in accordance with the Creative Commons Attribution Non Commercial (CC BY-NC 4.0) license, which permits others to distribute, remix, adapt, build upon this work non-commercially, and license their derivative works on different terms, provided the original work is properly cited and the use is non-commercial. See: http://creativecommons.org/ licenses/by-nc/4.0/

(C) Article author(s) (or their employer(s) unless otherwise stated in the text of the article) 2018. All rights reserved. No commercial use is permitted unless otherwise expressly granted.

\section{REFERENCES}

1. Canadian Institute for Health Information. Health Care in Canada 2011: a focus on seniors and aging. Ottawa: Canadian Institute for Health Information, 2011.

2. Sampson EL, Blanchard MR, Jones L, et al. Dementia in the acute hospital: prospective cohort study of prevalence and mortality. $\mathrm{Br} \mathrm{J}$ Psychiatry 2009;195:61-6.

3. Gray LC, Peel NM, Costa AP, et al. Profiles of older patients in the emergency department: findings from the interrai multinational emergency department study. Ann Emerg Med 2013;62:467-74.

4. Launay C, Haubois G, Hureaux-Huynh R, et al. Older adults and emergency department: who is at risk of hospitalization?. Geriatr Psychol Neuropsychiatr Vieil 2014;12:43-9.
5. Clevenger CK, Chu TA, Yang Z, et al. Clinical care of persons with dementia in the emergency department: a review of the literature and agenda for research. J Am Geriatr Soc 2012;60:1742-8.

6. Sirois M-J, Émond M, Ouellet M-C, et al. Cumulative incidence of functional decline after minor injuries in previously independent older Canadian individuals in the emergency department. J Am Geriatr Soc 2013;61:1661-8

7. World Health Organisation. International Classification of Diseases (ICD-10). 2016. http://apps.who.int/classifications/icd10/browse/ 2016/en\#/T66-T78

8. Albert M, McCaig LF, Ashman JJ. Emergency department visits by persons aged 65 and over: United States, 2009-2010. Hyattsville 2013. http://www.ncbi.nlm.nih.gov/pubmed/24152709

9. Ng W, Fujishima S, Suzuki M, et al. Characteristics of elderly patients presenting to the emergency department with injury. Keio $\mathrm{J}$ Med 2002;51:11-16.

10. Canadian Institute for Health Information. Seniors' use of emergency departments in Ontario. 2010. https://secure.cihi.ca/ estore/productFamily.htm?locale=en\&pf=PFC1398\&lang=en\& media $=0$

11. Ontario Injury Prevention Resource Centre. Injuries among seniors in Ontario: a descriptive analysis of emergency department and hospitalization data. $2007 \mathrm{http}: / /$ www.oninjuryresources.ca/ downloads/publications/seniors_report.pdf.

12. Fischer BL, Gleason CE, Gangnon RE, et al. Declining cognition and falls: role of risky performance of everyday mobility activities. Phys Ther 2014:94:355-62.

13. Tierney MC, Charles J, Naglie G, et al. Risk factors for harm in cognitively impaired seniors who live alone: a prospective study. $J$ Am Geriatr Soc 2004;52:1435-41.

14. Robitaille $\mathrm{Y}$, Laforest $\mathrm{S}$, Fournier $\mathrm{M}$, et al. Moving forward in fall prevention: an intervention to improve balance among older adults in real-world settings. Am J Public Health 2005;95:2049-56.

15. Nasvadi GE. Changes in self-reported driving behaviour following attendance at a mature driver education program. Transp Res Part $F$ Traffic Psychol Behav 2007;10:358-69.

16. Division of Aging and Seniors. An inventory of Canadian programs for the prevention of falls among seniors living in the community. Ottawa: Division of Aging and Seniors, 2001.

17. Levac D, Colquhoun H, O'Brien KK. Scoping studies: advancing the methodology. Implementation Science 2010;5:69.

18. Arksey H, O'Malley L. Scoping studies: towards a methodological framework. Int J Soc Res Methodol 2005;8:19-32.

19. Provencher V, Généreux M, Gagnon-Roy M, et al. Preventing avoidable incidents leading to a presentation to the emergency department $(E D)$ by older adults with cognitive impairment: protocol for a scoping review. BMJ Open 2016;6:e009818.

20. World Health Organisation. International Classification of Diseases (ICD-10). 2016

21. L'écuyer R. Méthodologie de l'analyse développementale de contenu. Méthode GPS et concept de soi. Québec: Presses de I'Université du Québec, 1990.

22. Shaw FE, et al. Multifactorial intervention after a fall in older people with cognitive impairment and dementia presenting to the accident and emergency department: randomised controlled trial. BMJ 2003;326:73.

23. Shaw FE. Falls in older people with dementia. Geriatr aging 2003;6:37-40.

24. Gagnon C, Lafrance M. Prévention des chutes auprès des personnes âgées vivant à domicile : recommandations prélimiaire à l'élaboration d'un guide de pratique clinique. 2011:235.

25. Public Health Agency of Canada. The safe living guide: a guide to home safety for seniors. 2011. http://www.phac-aspc.gc.ca/seniorsaines/publications/public/injury-blessure/safelive-securite/index-eng. php

26. Raina P, Torrance V, Lindsay J. A review of the literature and an analysis of mortality and hospitalisation data to examine patterns of injuries among Canadian seniors. 1997.

27. Public health agency of Canada. If you fall or witness a fall, do you know what to do? 2008. http://www.phac-aspc.gc.ca/seniors-aines/ publications/public/injury-blessure/falls-chutes/index-fra.php

28. Owens PL, Russo CA, Spector W, et al. Emergency department visits for injurious falls among the elderly, 2006: Statistical Brief \#80. 2006. http://www.ncbi.nlm.nih.gov/pubmed/21452495

29. Kara H, Bayir A, Ak A, et al. Trauma in elderly patients evaluated in a hospital emergency department in Konya, Turkey: a retrospective study. Clin Interv Aging 2013;17.

30. Marques de Abrantes KS, Nobre de Menezes T, Andrade Duarte de Farias MdoC, et al. Trauma in elderly people attended by a mobile emergency service. Int Arch Med 2015. 
31. Centers for Disease Control and Prevention. Older adult falls: get the facts. 2015. http://www.cdc.gov/homeandrecreationalsafety/falls/ad ultfalls.html

32. Public Health Agency of Canada. Report on seniors' falls in Canada. 2005. http://www.publications.gc.ca/pub?id=9.649855\&sl=0

33. Lee VMS, Wong TW, Lau CC. Home accidents in elderly patients presenting to an emergency department. Accid Emerg Nurs 1999;7:96-102

34. Yeo YY, Lee SK, Lim CY, et al. A review of elderly injuries seen in a Singapore emergency department. Singapore Med J 2009;50:278-83.

35. Aschkenasy MT, Rothenhaus TC. Trauma and falls in the elderly. Emerg Med Clin North Am 2006;24:413-32.

36. Lee J, Sirois M-J, Moore L, et al. Return to the ED and hospitalisation following minor injuries among older persons treated in the emergency department: predictors among independent seniors within 6 months. Age Ageing 2015;44:624-9.

37. Amador S, Goodman C, King D, et al. Emergency ambulance service involvement with residential care homes in the support of older people with dementia: an observational study. BMC Geriatr 2014;14:95.

38. Burns E. Older people in accident and emergency departments. Age Ageing 2001;30:3-6.

39. Ziminski CE, Phillips LR, Woods DL. Raising the index of suspicion for elder abuse: cognitive impairment, falls, and injury patterns in the emergency department. Geriatr Nurs 2012;33:105-12.

40. Public Health Agency of Canada. Seniors' falls in Canada: second report. 2014. http://www.phac-aspc.gc.ca/seniors-aines/ publications/public/injury-blessure/seniors_falls-chutes_aines/indexeng.php

41. Whiteman C, Tillotson R, Denne N, et al. Major trauma in West Virginia dementia patients injury patterns, discharge dispositions and implications for treatment and injury prevention. $W V$ Med $J$ 2011;107:48-52

42. Nourhashémi F, Andrieu S, Sastres N, et al. Descriptive analysis of emergency hospital admissions of patients with Alzheimer disease. Alzheimer Dis Assoc Disord 2001;15:21-5.

43. Voisin T, Sourdet S, Cantet C, et al. Descriptive analysis of hospitalizations of patients with Alzheimer's disease: a two-year prospective study of 686 patients from the REAL.FR study. J Nutr Health Aging 2009;13:890-2.

44. Ministry of health of B.C. Canada. The evolution of seniors' falls prevention in British Columbia: working strategically and collectively to reduce the burden and impact of falls and fall-related injury among seniors. 2006. http://www.health.gov.bc.ca/library/publications/year/ 2006/falls report.pdf

45. Kihlgren A, Wimo A, Mamhidir A-G. Older patients referred by community nurses to emergency departments: a descriptive crosssectional follow-up study in a Swedish context. Scand J Caring Sci 2014;28:97-103.

46. Pfortmueller CA, Kunz M, Lindner G, et al. Fall-related emergency department admission: fall environment and settings and related injury patterns in 6357 patients with special emphasis on the elderly. ScientificWorldJournal 2014;2014:1-6.

47. Timler D, Dworzyński MJ, Szarpak Ł, et al. Head trauma in elderly patients: mechanisms of injuries and CT findings. Adv Clin Exp Med 2015;24:1045-50.

48. Ministry of health planning Office of the Provincial Health Officer British Columbia. Prevention of falls and injuries among the elderly : a special report from the Office of the Provincial Health Planning. 2004. http://www.health.gov.bc.ca/library/publications/year/2004/ falls.pdf

49. Department of Health Promotion and Protection. Preventing fallrelated injuries among older nova scotians : a strategic framework. 2007.

50. Gyllencreutz L, Björnstig J, Rolfsman E, et al. Outdoor pedestrian fall-related injuries among Swedish senior citizens: injuries and preventive strategies. Scand J Caring Sci 2015;29:225-33.

51. Wilkins K, Park E. Injuries: heal reports, Stat Canada, 2004:43-8.

52. Douglas A, Letts L, Richardson J. A systematic review of accidental injury from fire, wandering and medication self-administration errors for older adults with and without dementia. Arch Gerontol Geriatr 2011;52:e1-10.

53. Taylor ME, Delbaere K, Lord SR, et al. Neuropsychological, physical, and functional mobility measures associated with falls in cognitively impaired older adults. J Gerontol A Biol Sci Med Sci 2014;69:987-95

54. Paniagua MA, Malphurs JE, Phelan EA. Older patients presenting to a county hospital ED after a fall: missed opportunities for prevention. Am J Emerg Med 2006;24:413-7.

55. Ouellet M-C, Sirois M-J, Beaulieu-Bonneau S, et al. Correlates of cognitive functioning in independent elderly patients discharged home from the emergency department after a minor injury. Int Psychogeriatr 2016;28:1313-22.

56. Welmerink DB, Longstreth WT, Lyles MF, et al. Cognition and the risk of hospitalization for serious falls in the elderly: results from the Cardiovascular Health Study. J Gerontol A Biol Sci Med Sci 2010;65A:1242-9.

57. Taylor ME, Lord SR, Brodaty H, et al. A home-based, carerenhanced exercise program improves balance and falls efficacy in community-dwelling older people with dementia. Int Psychogeriatr 2017;29:81-91.

58. National Institute on Aging. Falls and fractures. 2009. https://www. nia.nih.gov/health/publication/falls-and-fractures

59. Beaudoin FL, Merchant RC, Clark MA. Prevalence and detection of prescription opioid misuse and prescription opioid use disorder among emergency department patients 50 years of age and older: performance of the prescription drug use questionnaire, patient version. The American Journal of Geriatric Psychiatry 2016;24:627-36.

60. Mahoney JE, Shea TA, Przybelski R, et al. Kenosha county falls prevention study: a randomized, controlled trial of an intermediateintensity, community-based multifactorial falls intervention. J Am Geriatr Soc 2007;55:489-98.

61. National Institute on Aging. Driving and dementia: health professionals can play important role. 2002. https://www.nia.nih.gov/ alzheimers/features/driving-and-dementia-health-professionals-canplay-important-role

62. Alden NE, Rabbitts A, Yurt RW. Burn injury in patients with dementia: an impetus for prevention. J Burn Care Rehabil 2005;26:267-71.

63. Ehrlich AR, Kathpalia S, Boyarsky Y, et al. Elderly patients discharged home from the emergency department with minor burns. Burns 2005;31:717-20.

64. Lowton K, Laybourne AH, Whiting DG, et al. Can fire and rescue services and the National Health Service work together to improve the safety and wellbeing of vulnerable older people? Design of a proof of concept study. BMC Health Serv Res 2010;10:327.

65. Lester PE, Kohen I. Smoking in the nursing home: a case report and literature review. J Am Med Dir Assoc 2008;9:201-3.

66. Elder AT, Squires T, Busuttil A. Fire fatalities in elderly people. Age Ageing 1996;25:214-6

67. Tierney MC, Snow WG, Charles J, et al. Neuropsychological predictors of self-neglect in cognitively impaired older people who live alone. The American Journal of Geriatric Psychiatry 2007;15:140-8.

68. Charles J, Naglie G, Lee J, et al. Self-report measures of well-being predict incident harm due to self-neglect in cognitively impaired seniors who live alone. J Alzheimers Dis 2015;44:425-30.

69. Barat I, Andreasen F, Damsgaard EMS. Drug therapy in the elderly: what doctors believe and patients actually do. Br J Clin Pharmacol 2001;51:615-22.

70. Canadian Institute for Health Information. Hospitalizations and emergency department visits due to opioid poisoning in Canada. 2016. https://secure.cihi.ca/free_products/Opioid Poisoning Report EN.pdf

71. Tierney MC, Charles J, Jaglal S, et al. Identification of those at greatest risk of harm among cognitively impaired people who live alone. Aging, Neuropsychology, and Cognition 2001;8:182-91.

72. Rowe MA, Feinglass NG, Wiss ME. Persons with dementia who become lost in the community: a case study, current research, and recommendations. Mayo Clin Proc 2004;79:1417-22.

73. Valcour VG, Masaki KH, Blanchette PL, et al. Cognitive status, and physician awareness of cognitive impairment. J Am Geriatr Soc 2002;50:1265-7.

74. Lafont S, Laumon B, Helmer C, et al. Driving cessation and selfreported car crashes in older drivers: the impact of cognitive impairment and dementia in a population-based study. J Geriatr Psychiatry Neurol 2008;21:171-82.

75. Dalsania P. Dementia dashboard: a proactive risk reduction management guideline. Top Geriatr Rehabil 2006;22:228-42.

76. Frittelli C, Borghetti D, ludice G, et al. Effects of Alzheimer's disease and mild cognitive impairment on driving ability: a controlled clinical study by simulated driving test. Int $J$ Geriatr Psychiatry 2009;24:232-8.

77. Withaar FK, Brouwer WH, Van Zomeren AH. Fitness to drive in older drivers with cognitive impairment. Journal of the International Neuropsychological Society 2000;6:480-90.

78. Booth V, Logan P, Harwood R, et al. Falls prevention interventions in older adults with cognitive impairment: a systematic review of reviews. Int J Ther Rehabil 2015;22:289-96.

79. Wilber ST, Lofgren SD, Mager TG, et al. An evaluation of two screening tools for cognitive impairment in older emergency department patients. Academic Emergency Medicine 2005;12:612-6. 
80. Carpenter CR, DesPain B, Keeling TN, et al. The Six-Item Screener and AD8 for the detection of cognitive impairment in geriatric emergency department patients. Ann Emerg Med 2011;57:653-61.

81. Lee JS, Verbeek PR, Schull MJ, et al. Paramedics assessing Elders at Risk for Independence Loss (PERIL): derivation, reliability and comparative effectiveness of a clinical prediction rule. CJEM 2016;18:121-32.

82. Taylor ME, Delbaere K, Close JCT, et al. Managing falls in older patients with cognitive impairment. Aging health 2012;8:573-88.

83. Al-Aama T, Tareef A-A. Falls in the elderly : spectrum and prevention. Can Fam physician 2011;57:771-6.

84. Institut national de santé publique du Québec. Prévenir les chutes chez les aînés vivant à domicile: Volet soutien à domicile-Intervention multifactorielle personnalisée [IMP]. 2017.

85. Fuller GF. Falls in the elderly. Am Fam Physician 2000;61:2159-68.
86. Rapp K, Lamb SE, Büchele G, et al. Prevention of falls in nursing homes: subgroup analyses of a randomized fall prevention trial. J Am Geriatr Soc 2008;56:1092-7.

87. Canadian Institute for Health Information. Sources of potentially avoidable emergency department visits. 2014. https://secure.cihi.ca/ free_products/ED_Report_ForWeb_EN_Final.pdf

88. Alldred DP, Raynor DK, Hughes C, et al. Interventions to optimise prescribing for older people in care homes. Alldred DP, ed. Cochrane database of systematic reviews. Chichester, UK: John Wiley \& Sons, Ltd, 2013.

89. Carpenter CR, Avidan MS, Wildes T, et al. Predicting geriatric falls following an episode of emergency department care: a systematic review. Academic Emergency Medicine 2014;21:1069-82.

90. Canada PHA of Public Health Agency of Canada. The national blueprint for injury prevention in older drivers. 2009. 